\title{
Effects of using innovative seismic isolation technique on masonry: tunnelling work required
}

\author{
B. A. Zeeshan, A. De Stefano \& S. Invernizzi \\ Department of Structural, Geotechnical and Building Engineering, \\ Politecnico di Torino, Italy
}

\begin{abstract}
Seismic upgrading of historical, industrial and other important buildings is a major challenge faced by engineers. An innovative method of base isolation was proposed by Clemente and De Stefano ("Application of seismic isolation in the retrofit of historical buildings" (2011)), requiring construction of closely spaced micro-tunnels under the entire width of a building. This paper addresses the issue of damage assessment of the masonry due to the ground subsidence that will result from the construction of microtunnels. The parametric finite element approach is adopted to study the susceptibility of masonry to damage, considering stiffness of soil and masonry, openings in masonry, depth of tunnels, construction sequence of tunnels and behavior of soil-structure interface. Coupled analysis is performed and plain strain conditions are assumed for the simulation of tunnel construction. The damage sustained by the masonry is categorized; feasible construction conditions are highlighted, and preventive measures are proposed for unfavourable situations. It is concluded that this method can be used for the seismic isolation of structures in a variety of soil conditions.

Keywords: microtunnelling, seismic isolation, damage assessement, parametric study, soil-structure interaction, closely spaced, multiple tunnels.
\end{abstract}

\section{Introduction}

Seismic upgrading of buildings is one the task at the hands of structural engineers. There are many techniques of upgrading buildings for seismic actions: such as conventional methods, use of innovative materials and installation of 
passive control devices. These techniques require us to either add some structural elements, or strengthen existing structural elements. Although these techniques are effective, they are not suitable for some historical buildings, and industrial installations having complex network of pressure pipes.

A new method has been proposed by Clemente and De Stefano [1] for isolating a building from seismic actions. Their idea is to isolate certain part of soil, under and around the building, from the rest of the soil by constructing a trench and closely spaced microtunnels: Trench will surround the entire building, while tunnels will be under foundation, covering the entire width of building (fig. 1).

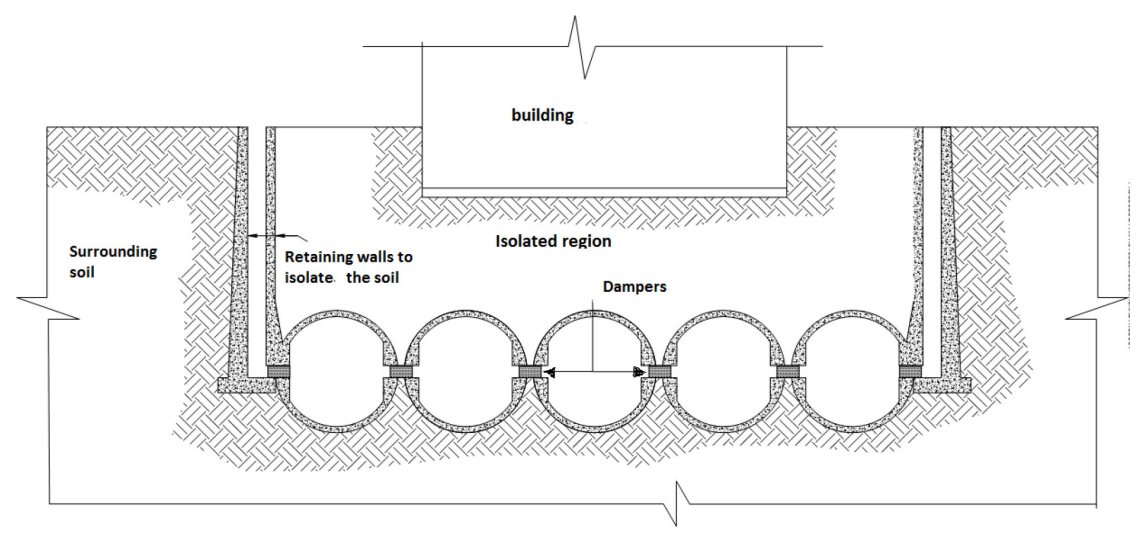

Figure 1: Schematic of innovative seismic isolation technique [13].

Tunneling works, required for this method, will result in differential settlement of the structure above it. These settlements can damage the structure and associated service utilities; hence it is important to predict the settlements induced by tunneling as well as the resulting damage to validate the applicability of this technique.

In literature, many empirical-analytical methods [2-4], are available for evaluating damage assessment due to the ground subsidence, induced by multiple tunnels. These methods require parameters of green field settlements, which can be computed by using either empirical relations [5-8] or analytical relations [9].

Empirical-analytical techniques are useful for quick assessment, but are limited in their use: they cannot account for material nonlinearities, soil-structure interaction and weight/stiffness of structures [4, 10]. Researchers, such as Netzel [10] and Franzius et al. [11], have improved the empirical-analytical techniques by considering the effects of soil-structure interaction, stiffness and weight of structure. Although, these techniques are useful but a better estimate is possible by considering nonlinear behavior of masonry, soil and interface through numerical techniques.

Aim of this paper is to access damage posed by the construction of closely spaced micro tunnels using non-linear finite element analysis, and thus assessing 
suitability of this base isolation technique. A parametric study is conducted on DIANA 9.4.4, and the behavior of masonry wall with a particular ductility (fracture energy is kept constant) is assessed. Factors such as tunnel depth, stiffness of soil, stiffness of masonry, construction sequence, presence of openings in masonry, and soil-structure interaction have been taken into account. The damage suffered by the masonry wall, after the completion of excavation process, is categorized according to the criteria set by Burland et al. [12]; suitable soil conditions are highlighted and some preventive measures have been proposed.

\section{Analysis methodology}

\subsection{Parametric study: overview}

The behaviour of the masonry and damage sustained by the masonry is assessed by conducting a parametric study. Numerous numerical models are analysed for the said purpose, and these models are grouped into following categories:

- Category 1: solid wall coupled with $5 \mathrm{~m}$ deep tunnel-assembly.

- Category 2: solid wall coupled with tunnel-assembly at $9 \mathrm{~m}$ depth.

- Category 3: wall with openings for door and windows, and coupled with $5 \mathrm{~m}$ deep tunnel-assembly.

- Category 4: wall with openings for doors and windows, and coupled with $9 \mathrm{~m}$ deep tunnel-assembly.

- Category 5: category of models (1-4) analysed with altered sequence of tunnel construction (fig. 2).

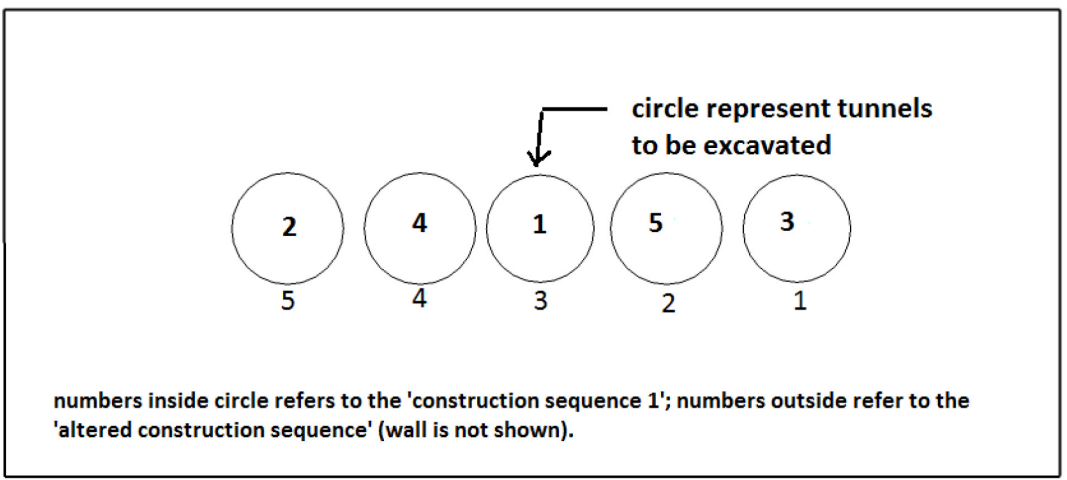

Figure 2: $\quad$ Construction sequence adopted in this study.

The category of models 1 to 4 is analysed with a sequence of tunnel construction dubbed as 'construction sequence 1' (see fig. 2); two types of wall properties are considered for each category: one representing stiffer masonry, and the other representing historic masonry. In all the models, soil structure 
interaction is taken into account by incorporating interface elements: smooth as well as rough interface is considered. Stiffness of soil is taken into account by changing its elastic modulus in each category of numerical models; parameters defining strength of soil (cohesion and friction angle) are kept constant in the entire study.

\subsection{Problem geometry, constraints, loads, discretization of model}

As discussed in previous section, two situations are considered relating to depth of tunnels: one group of tunnels at $5 \mathrm{~m}$ and the other one at $9 \mathrm{~m}$. The diameter of all tunnels (five tunnels) is $2 \mathrm{~m}$; they are closely spaced, and the distance between their centre lines is $2.2 \mathrm{~m}$. The bottom boundary of the problem is kept at about $4 \mathrm{D}$ from the tunnel centre line and boundaries at the sides are at $6 \mathrm{D}$ from the centre of the edge tunnels.

The bottom boundary is constrained in $\mathrm{Y}$ direction and side boundaries are restricted in $\mathrm{x}$ directions. Top boundary is free to move in both directions.

In all models, wall height is kept constant, $7.0 \mathrm{~m}$; the length of wall is $11.4 \mathrm{~m}$; and its thickness is $0.22 \mathrm{~m}$.

In addition to self-weight, a superimposed line load is applied on the wall: $8 \mathrm{kN} / \mathrm{m}$ on first as well as on roof level.

Soil is discretized using 8-noded quadrilateral plane-strain elements, masonry as 8-noded quadrilateral plane-stress elements, tunnel lining by 3-noded curved shell elements and lintel as 3-noded two dimensional class III beam elements. The soil around tunnel openings is discretized using 6-noded triangular planestrain elements; interface by using 2-D line interface elements.

\subsection{Material modelling and properties}

Soil is modelled as homogeneous, isotropic, linear-elastic perfectly-plastic material with Mohr-Coulomb yield surface and tension cut-off. The behaviour of masonry with respect to the soil stiffness is assessed by varying elastic modulus of soil; four values are used: $170 \mathrm{MPa}, 100 \mathrm{MPa}, 50 \mathrm{MPa}$ and $30 \mathrm{MPa}$. Other soil properties are: unit weight of soil is $18 \mathrm{KN} / \mathrm{m}^{3}$, cohesion is $72 \mathrm{KPa}$, Poisson's ratio 0.3 , friction and dilatancy angles are $15^{\circ}$ and 0 , respectively, and Ko is 0.47. A very small number is adopted for the tensile strength of the soil as it is weak in tension.

Masonry is modelled as a homogeneous and isotropic material. In an elastic regime, masonry is assumed to behave in a linear-elastic manner; while a smeared crack approach with strain decomposition is used to simulate its behaviour in cracking. A fixed-crack model with linear tension softening and constant tension cut-off criteria (see fig. 3), is used to simulate crack initiation and propagation; shear retention factor is chosen as 0.01 .

Uniform thickness of $220 \mathrm{~mm}$ is adopted for masonry. The default value of DIANA is used for the crack band width, which is based on the area of element and integration scheme. Values chosen for fracture energy and Poisson's ratio are $50 \mathrm{~N} / \mathrm{m}$ and 0.2 , respectively, while density is taken as $2100 \mathrm{Kg} / \mathrm{m}^{3}$. Historic and stiffer masonry are differentiated by their elastic modulus and tensile 


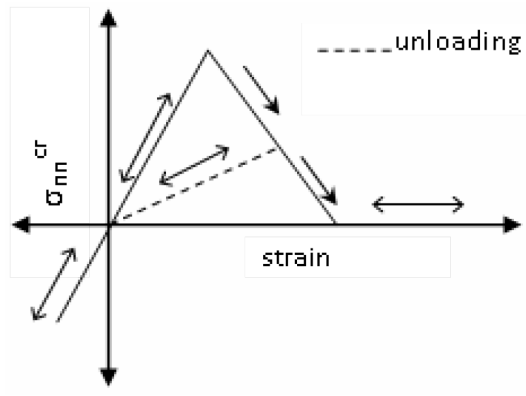

Figure 3: $\quad$ Linear tension softening model for masonry.

strength. For stiffer masonry, elastic modulus is $4.5 \mathrm{GPa}$ and tensile strength is $200 \mathrm{kPa}$; while it is $2 \mathrm{GPa}$ (elastic modulus) and $150 \mathrm{kPa}$ (tensile strength) for historic masonry.

The interaction between soil and masonry is modelled by using interface elements: they relate normal and shear forces to normal and shear relative displacements across interface. Mohr-Coulomb law in combination with tension cut-off (figs 4 and 5) is used to model the relative slip and the gap.

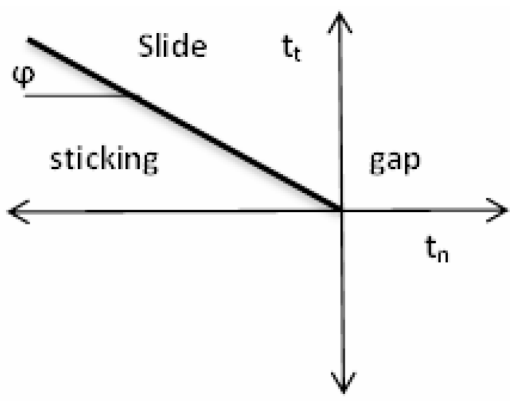

Figure 4: Mohr-Coulomb surface for interface.

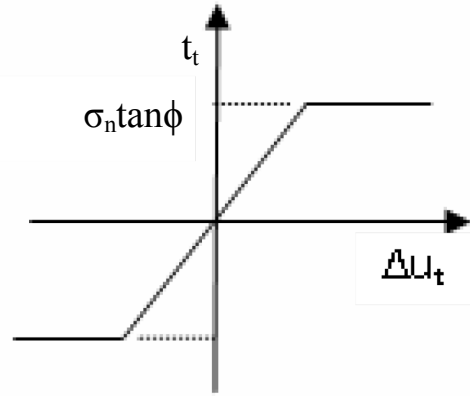

Figure 5: Shear behaviour of interface.

A nonlinear interface is used for the rough interface; the parameters used for Mohr-coulomb model are, cohesion: 0, friction angle: $22^{\circ}$, tensile strength: 0 , and normal and shear stiffness is $2.5 \times 10^{8} \mathrm{~N} / \mathrm{m}^{3}$ and $1.5 \times 10^{8} \mathrm{~N} / \mathrm{m}^{3}$, respectively, for the rough case. Properties chosen for the non-linear smooth interface are: cohesion and tensile strength is 0 , friction angle is $1^{\circ}$, normal stiffness is taken as $2.5 \times 10^{8} \mathrm{~N} / \mathrm{m}^{3}$; while a very small value $\left(1 \mathrm{~N} / \mathrm{m}^{3}\right)$ is chosen for shear stiffness.

The lining and the lintel is modelled as linear-elastic, isotropic and homogeneous material. Material parameters adopted for lining are: density $2400 \mathrm{~kg} / \mathrm{m}^{3}$, elastic modulus $21 \mathrm{GPa}$, Poisson's ratio 0.15 and the thickness used is $100 \mathrm{~mm}$. For the lintel, material properties are: density $2400 \mathrm{~kg} / \mathrm{m}^{3}$, elastic modulus 15GPa, Poisson's ratio 0.15 and the cross-section of $0.22 \times 0.16 \mathrm{~m}$. Dampers are not included in numerical model in order to simplify the problem. 


\subsection{Simulation of construction process}

Initial soil stresses are established first, which are based on unit weight of soil and coefficient of earth pressure at rest; displacements are suppressed in this phase. In the next step, masonry elements are activated along with their selfweight and superimposed load. This phase is named as 'pre-excavation phase' for the sake of reference. Next step is the simulation of tunnel construction, one tunnel will be constructed at a time. The simulation of tunnel construction has been done in two steps: modelling of excavation and installation of lining.

Excavation simulation involves removal of excavation elements as well as simulation of volume loss. Since, tunnel size is small and soil is relatively stiff, annular space is the main source of volume loss. Volume loss is simulated by allowing the tunnel to undergo instantaneous settlement, with no pressure applied on excavated boundary, before the installation of lining elements (the remaining annular space to be filled with grout). Same procedure is applied for all tunnels throughout this study.

\section{Results}

\subsection{Category 1 and 2 models: wall without openings}

The case of smooth interface will be discussed first. Of the two wall types, historic masonry sustained more damage: the maximum crack width of about $0.5 \mathrm{~mm}$ is obtained when it is coupled with the soil of $30 \mathrm{MPa}$ elastic modulus. This damage can be categorized as 'very slight' [12]. Stiffer masonry experienced hairline cracks on 30MPa (elastic modulus) soil, and its damage can be categorized as 'negligible'. The result holds for the tunnel excavation at the depth of 5 as well as 9 metres.

The maximum damage appeared at bottom centre of wall, see ; distribution of stresses is similar to that of flexural behavior of beam: tension at bottom and compression a top. The wall experienced hogging stresses as well, but only at the top corners (spread on less than 2 meter length).

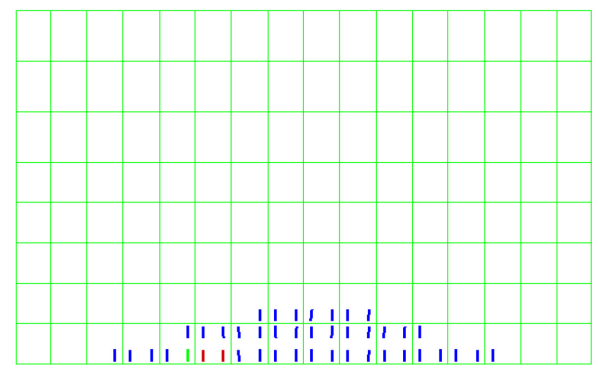

Figure 6: Crack distribution: wall on $30 \mathrm{MPa}$ (elastic modulus) soil. 
Figure 6 shows the distribution of cracks in the historic wall; cracks are in vertical direction which means principle tensile stresses are horizontal.

No crack appeared when the solid wall is modelled with rough interface, and most part of the wall remained in compression.

Tunnelling in the less stiffer soil inflicted more damage than the stiffer soil (fig. 7), as stiffness of soil affects the volume loss.

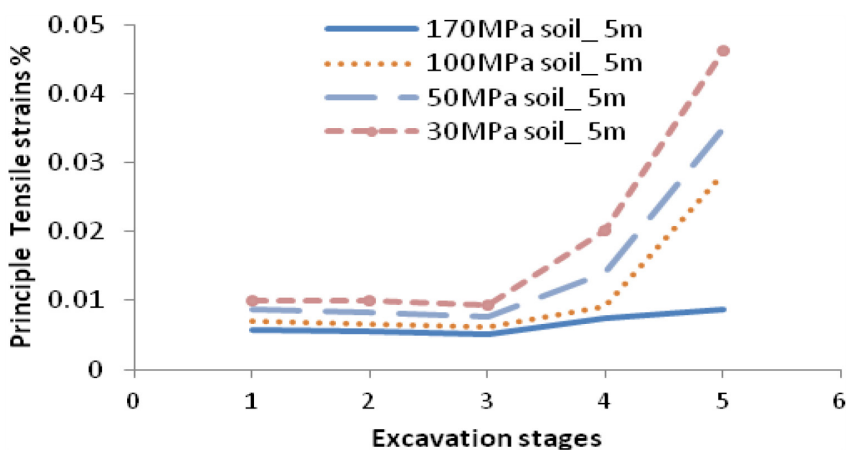

Figure 7: $\quad$ Principle tensile strain vs. excavation stages (smooth interface).

Figure 7 shows that there is negligible increase in damage, expressed in term of maximum principle tensile strain, from excavation 1 to excavation 3 ; a significant increase in damage is noted from excavation of the $4^{\text {th }}$ tunnel to the $5^{\text {th }}$ tunnel. First three tunnels are spaced at a bit more than a diameter distance, while the last two tunnels sit in between first three tunnels; resulting in significant increase of deflection ratio and hence damage. Excavation stages, in fig. 7, refer to the phase of lining installation. The wall coupled with $170 \mathrm{MPa}$ (elastic modulus) soil remained elastic throughout the excavation process, as indicated by the relatively straight solid line (fig. 7).

\subsection{Category 3 and 4 models: wall with openings for door/windows}

\subsubsection{Stiffer masonry}

In the case of smooth interface, the stiffer masonry sustained a damage that can be categorized as 'very slight' [12] on soils with elastic modulus of $170 \mathrm{MPa}$ and $100 \mathrm{MPa}$, while it sustained 'slight' damage on 50 and $30 \mathrm{MPa}$ (elastic modulus) soil. The result holds for the tunnel-assembly at $9 \mathrm{~m}$ as well as $5 \mathrm{~m}$ depth. The wall sustained maximum damage when it is coupled with $30 \mathrm{MPa}$ (elastic modulus) soil; corresponding crack width is about $3.5 \mathrm{~mm}$.

The masonry wall sustained no cracks in the case of rough interface; it experienced maximum tensile stresses at top corners.

The bottom centre of the wall is the most damaged area in the case of smooth interface. The crack distribution for one the cases, wall on $30 \mathrm{MPa}$ (elastic modulus) soil, is shown in fig. 8. The ovals, shown in the fig. 8 , indicate the area of the wall that is most stressed in tension; most of the other cracks, outside 
indicated areas, are hairline (less than $0.1 \mathrm{~mm}$ in width). It can be expected that, the masonry will either fail by tension cracks in head joints, or combined failure of head joint and brick units, if it is subjected to further stress.

By comparing the sensitivity of the wall to the depth of tunnel construction, a marginal difference is observed. However, stiffness of soil made significant effect on the damage susceptibility of the masonry wall to the tunnel related deformation. Figure 9 shows the deflection ratios of the wall after the completion of each tunnel; comparing results against the depth of construction as well as the stiffness of soil.

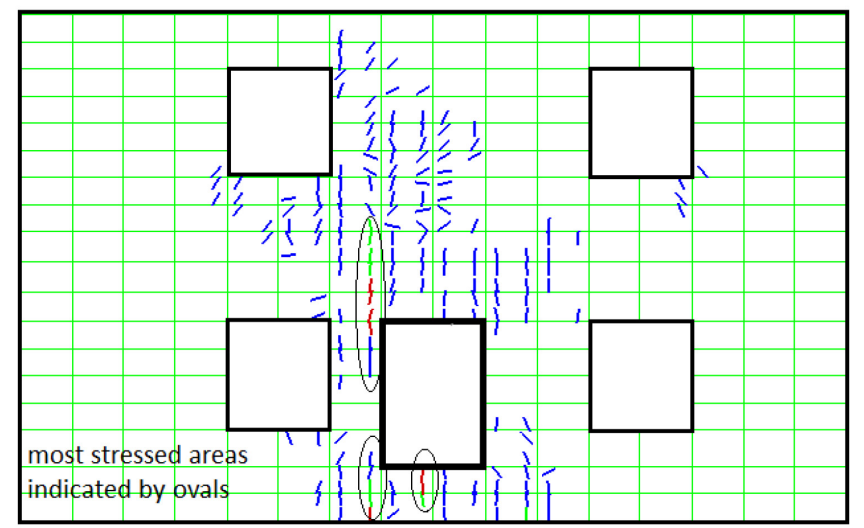

Figure 8: Crack distribution (soil's elastic modulus 30MPa).

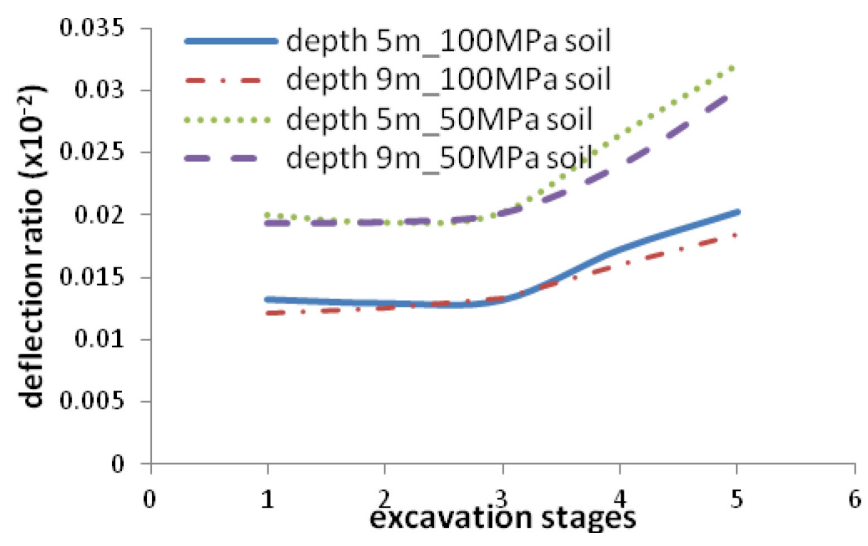

Figure 9: Deflection ratio vs. excavation stages.

\subsubsection{Historic masonry}

This wall sustained 'severe' damage when coupled with soil stiffness of 50 and $30 \mathrm{MPa}$; it sustained 'moderate' damage on soil with elastic modulus of $100 \mathrm{MPa}$, and 'slight' damage on 170MPa soil. 
The rough interface helped the masonry wall to endure ground deformations without sustaining any cracks.

Figure 10 indicates (oval shapes) the most damaged area of the wall for the case of least stiff soil (30MPa), and modelled with smooth interface. The ground deformation will tend to divide the wall into two halves by cracking it along the door opening, as shown in fig. 10. Tensile stresses parallel to the bed joints will result in cracking of head joint, brick units, or both, depending upon the arrangement of bricks and the relative strengths of mortar and brick.

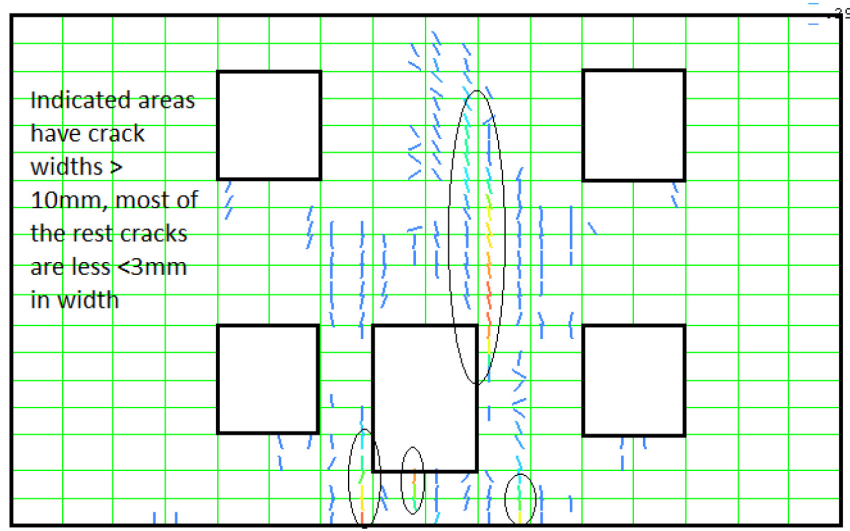

Figure 10: Direction and distribution of cracks.

The localization of damage resulted in the sharp increase of crack widths, as shown in fig. 11 , for the wall on the least stiff soil (30MPa : elastic modulus). The crack widths increased very sharply at $4^{\text {th }}$ and $5^{\text {th }}$ excavation stages. The ' 0 ' in fig. 11 refers to the pre-excavation phase: activation of soil, wall and lintel elements.

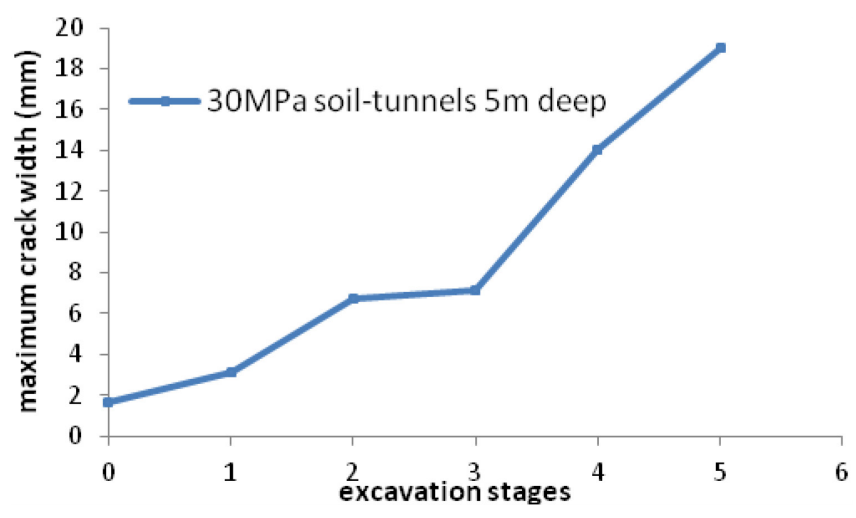

Figure 11: Crack width vs. excavation stages. 


\subsection{Category 7 models: effect of construction sequence}

In this set of numerical models, the wall with the door-window openings was analysed with altered construction (see fig. 2). Only the condition of smooth interface, and 9-meter deep tunnel-assembly, is considered to study the effect of construction sequence on the damage susceptibility of masonry.

The results showed that the sequence of tunnel construction will affect the behavior of masonry. Of the two permutations of tunnel-assembly considered in this study, altered construction sequence resulted in comparatively more damage. This increase in damage is due to the tilt, and increased deflection ratio, experienced by the wall when subjected to the altered sequence of excavation; tilt induces direct tensile stresses in the wall in addition to the bending stresses and horizontal stresses induced by deformed ground. The location of maximum settlement point changed when the tunnel-assembly was subjected to altered construction sequence. Figure 12 compares the maximum crack width experienced by the wall as the construction advanced from first to fifth tunnel.

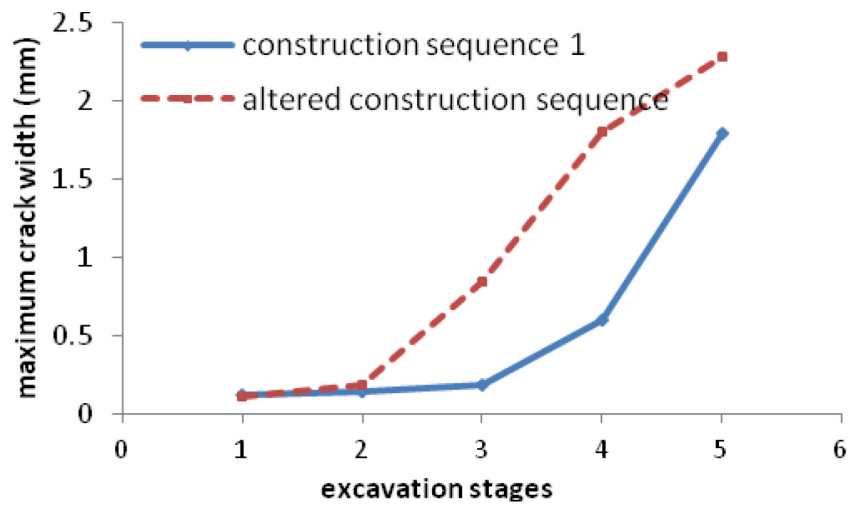

Figure 12: Crack widths vs. excavation stages - 50MPa soil.

\section{Conclusions}

In the light of study, the following conclusions can be drawn:

- Masonry, without openings and negligible initial damage, will not suffer any tunnel related damage on a variety of soil types.

- Masonry constructed with modern construction practices, adhering to the building codes, should be able to resist significant damage, if the diameter of the tunnel is less than $2.5 \mathrm{~m}$. Historic masonry with openings, will sustain tunnel related damage, depending upon the stiffness of soil and diameter of tunnels.

- Construction of this system in soils, with elastic modulus of less than (or equal to) $50 \mathrm{MPa}$, can produce treatable visible cracks (which can easily be filled) in the masonry constructed with modern construction practices; 
functional/severe damage in a very weak masonry is expected if the soil's elastic modulus is less than 100MPa. This conclusion is made in the light of elastic behavior of soil, observed in this study, maximum plastic radius around lining is less than $1.5 \mathrm{~m}$. Consequently, if strength parameters are less than the ones considered in this study, and if the diameter of tunnels is more than $2 \mathrm{~m}$, then a re-assessment is needed.

- Rough interface is able to prevent damage, while smooth interface does not prevent damage.

- The construction sequence of tunnel assembly also affects the damage sustained by the masonry; the construction sequence which reduces the tilt, should be preferred. The effect of the scheme of tunnel construction could be marginal or significant depending upon the damage criteria adopted for particular building.

\section{Preventive measures and recommendations}

It should be noted that this study only dealt with the situation of instant settlements under constant loads; annular gap can close after the lining has been placed. Hence, it is recommended to use grouting to fill the annular gap.

Although plain strain analysis gives a fair estimate of behaviour if there is no issue of instability in front and on crown of the tunnel. However, out of plane forces and the behaviour under longitudinal settlement cannot be accessed simultaneously without 3-D analysis, which will give better insight into the behaviour of the superstructure.

Feasibility of this method can be accessed for other opening configurations in wall; effect of wall height and length can be taken into the account; effect of strength parameters of soil can also be taken into the account.

Soil reinforcement techniques can be used for weaker soils having low stiffness. Numerous soil reinforcing techniques have been used in the past, such as soil freezing.

\section{References}

[1] P. Clemente and A. De Stefano, "Application of seismic isolation in the retrofit of historical buildings," Proc. of Earthquake Resistant Engineering Structures, Chianciano, pp. 41-52, 2011.

[2] M. Boscardian and E. J. Cording, "Building response to excavation-induced settlement," ASCE-Journal of Geotechnical Engineering, vol. 115, no. 1, pp. 1-21, 1989.

[3] J. B. Burland and C. P. Wroth, "Settlement of buildings and associated damage," Proc. of Settlement of Structures, Cambridge, pp. 611-654, 1974.

[4] D. M. Potts and T. I. Addenbrooke, "A structure's influence on TunnelingInduced ground movements," ICE-Journal of Geotechnical Engineering, vol. 125 , no. 2 , pp. 109-125, 1997. 
[5] T. I. Addenbrooke and D. M. Potts, "Twin tunnel interaction-surface and subsurface effects," International Journal of Geomechanics, vol. 1, pp. 249-271, 2001.

[6] M. P. O'Reilly and B. M. New, "Settlements above tunnels in United Kingdom: their magnitude and prediction," in Proceeding of Tunneling, pp. 55-64, 1982.

[7] D. N. Chapman, S. K. Ahn, D. Hunt and A. Chan, "The use of model test to investigate the ground displacements associated with multiple tunnel construction in soil," Tunnelling and Undergound Space Technology, vol. 21, no. 3-4, pp. 413-413, 2006.

[8] R. D. Peck, "Deep excavations and tunneling in soft ground," in Proceeding 7th International conference on soil mechanics and foundation engineering, pp. 225-290, 1969.

[9] C. Sagaseta, A. Lopez, J. Gomez and R. Pina, "soil deformation due to the excavation of two parallel caverns," in 12th European Conference on Soil Mechanics and Geotechnical Engineering, Amsterdam, pp. 2125-2131, 1999.

[10] H. Netzel, "Building response due to ground movements," IOS Press, 2009.

[11] J. N. Franzius, D. M. Potts and J. B. Burland, "The response of structures to tunnel construction," ICE- Journal of Geotechnical Engineering, vol. 159, no. 1, pp. 3-17, 2006.

[12] J. Burland, B. Broms and V. De Mello, "Behaviour of foundations and structures," in SOA report, session 2, Proc. 9th Conf. SMFE, Tokyo, pp. 495-546, 1977.

[13] P. Clemente, A. De Stefano and G. Barla, "Seismic Isolation system for existing building". Italy Patent PCT/IB2011/000716, 2011.

[14] J. G. Rots, "Comparative study of crack models," in Third DIANA World Conference, Tokyo, Japan, pp. 17-28, 2002.

[15] J. G. Rots and S. Invernizzi, "Regularized sequentially linear saw-tooth softening model," International Journal for Numerical and Analytical Methods in Geomechanics, vol. 28, pp. 821-856, 2004. 